\title{
Rancang Bangun Smart Dispenser Untuk Penyandang Tunanetra Menggunakan Pola Pengenalan Suara (Voice Recognition) Dengan Algoritma Fast Fourier Transform (FFT) Dan Autocorrelation
}

\author{
Asrori Firman Mawardi ${ }^{1}$, Achmad Ubaidillah ${ }^{2}$, Kunto Aji Wibisono ${ }^{3}$ \\ Program Studi S1 Teknik Elektro, Universitas Trunojoyo Madura \\ Fakultas Teknik, Universitas Trunojoyo Madura
}

\section{Informasi Makalah}

Dikirim, 11 Maret 2020

Direvisi, 17 Juni 2020

Diterima, 30 Juni 2020

\section{Kata Kunci:}

Dispenser otomatis voice recognition Selenoid valve

\begin{abstract}
INTISARI
Tunanetra merupakan kondisi dimana indra penglihatan manusia sudah tidak lagi berfungsi secara normal, dapat diklasifikasikan menjadi dua kategori besar, yaitu buta total (totally blind) dan yang masih mempunyai sisa penglihatan (Low Vision). Dengan hilangnya fungsi penglihatan dari seseorang, maka penyandang tunanetra tersebut harus memaksimalkan indra yang lain, baik indra perasa, penciuman, maupun pendengaran agar penyandang tunanetra mampu melakukan segala sesuatu secara mandiri. Terlebih dalam kegiatan mengambil air minum. Dispenser merupakan sebuah perangkat elektronik pengolah air dalam galon agar dapat diminum baik panas ataupun dingin dengan cara manual. Dengan alasan tersebut, tercetuslah ide untuk membuat suatu sistem dispenser otomatis. Dalam penyusunan skripsi ini telah direalisasikan sebuah dispenser otomatis untuk mempermudah penyandang disabilitas dalam mengambil air minum. Dispenser otomatis ini menggunakan voice recognition sebagai starting sistem dengan perintah suara yang ditangkap oleh microphone ke pc dan file akan disimpan dalam format.wav. Terdapat beberapa teknik untuk pengenalan pola suara yang baik, seperti penggunaan pada metode VAD (Voice Activity Detection) dan FFT (Fast Fourier Transform) kemudian dicocokan oleh metode Autocorrelation dan akan masuk dalam pengambilan keputusan. Dari penelitian ini didapatkan tingkat akurasi sistem pengolahan suara tersebut yakni $68,89 \%$.
\end{abstract}

\begin{abstract}
Blindness is a condition that the human sense of vision is no longer functioning normally, it can be categorized in two conditions, namely very total (totally blind) and who still have residual vision. By the loss of visual function of a person, the blind person should maximize the other senses, both the sense of taste, smell, and hearing so that the blind can do everything independently. Especially in taking drinking water. Dispenser is an electronic device processing water in gallons so that it can be drunk both hot and cold manually. For this reason, an idea was created to create an automatic dispenser system. In making this paper, an automatic dispenser has been realized to facilitate disability in taking drinking water. This automatic dispenser uses voice recognition as a system starting with voice commands taken by the microphone to the PC and the file will be saved in format.wav. There are several techniques to confirm sound patterns that are good, such as the use of the VAD (Voice Activity Detection) and FFT (Fast Fourier Transform) methods which are then matched with the Autocorrelation method and will be included in decision making. On
\end{abstract}


this research, the completion rate of the sound processing system is $68.89 \%$.

\author{
Korespondensi Penulis: \\ Asrori Firman Mawardi, Achmad Ubaidillah, Kunto Aji Wibisono, Miftachul Ulum \\ Program Studi Teknik Elektro \\ Fakultas Teknik Universitas Trunojoyo Madura \\ JL. Raya Telang, PO BOX 2 Kamal, Bangkalan, 69162 \\ Email: firmanuhick@gmail.com ubaidillah.ms@trunojoyo.ac.id kunto.ajiw@ trunojoyo.ac.id \\ miftachul.ulum@trunojoyo.ac.id
}

\title{
1. PENDAHULUAN
}

Tunanetra adalah istilah umum yang digunakan kepada seseorang dengan kondisi mengalami gangguan atau hambatan penglihatan. Menurut Conor (dalam Nawawi, 2009), tunanetra mempunyai batasan dalam penglihatan. Kebutaan merupakan masalah serius yang ada di Indonesia. Informasi dari WHO tahun 2010 menyebutkan bahwa kebutaan di Indonesia menempati posisi kedua di dunia, dari 45 juta penduduk dunia yang mengalami kebutaan, 2,5 jutanya merupakan penduduk Indonesia. Sementara itu, data kementerian kesehatan RI (2013) menyatakan bahwa jumlah penderita kebutaan dan penglihatan lemah (low vision) di Indonesia mencapai 3 juta jiwa. Pada tahun 2013 jumlah penderita kebutaan tercatat lebih dari 900 ribu jiwa sedangkan penderita penglihatan lemah mencapai lebih dari 2,1 juta jiwa. Jumlah penglihatan lemah (low vision) dan kebutaan meningkat pesat pada penduduk kelompok umur 45 tahun ke atas dengan rata-rata peningkatan sekitar dua sampai tiga kali lipat setiap 10 tahunnya. Jumlah lemah penglihatan dan kebutaan tertinggi ditemukan pada penduduk kelompok umur 75 tahun ke atas sesuai dengan adanya peningkatan proses degeneratif pada pertambahan usia (BPDANP Kesehatan, 2013). Dengan hilangnya fungsi penglihatan dari seseorang, maka penyandang tunanetra tersebut harus memaksimalkan indra yang lain, baik indra perasa, penciuman, maupun pendengaran agar penyandang tunanetra mampu melakukan segala sesuatu secara mandiri. Seperti halnya dalam melakukan kegiatan pengambilan air minum. [1].

Dispenser merupakan teknologi buatan manusia yang digunakan sebagai tempat atau wadah penampung air minum dimana bertujuan untuk membantu manusia dalam flexybilitas penempatan maupun pengambilan air minum. Teknologi dispenser yang beredar dipasaran indonesia saat ini adalah dispenser Hot and Cool, yaitu dispenser yang digunakan dengan pilihan antara panas atau dingin dengan sebelumnya menekan tombol On untuk menghidupkan sistem pemanas atau pendingin air yang selanjutnya air minum dapat diambil dengan cara membuka kran dispenser air panas atau air dingin secara manual sesuai dengan yang dikehendaki. Dengan demikian suplay air merupakan kebutuhan yang penting bagi kelangsungan hidup manusia, tak terkecuali juga penyandang tunanetra. Namum penyandang tunanetra sering mengalami kendala dalam melakukan aktifitas seperti halnya mengambil air minum, tunanetra tidak dapat membedakan dimana letak kran air yang panas dan dingin, karena sifat asli dari dispenser adalah manual. [2].

Untuk mengatasi kelemahan dispenser manual tersebut, penelitian ini membahas tentang perancangan dispenser pengisi gelas otomatis menggunakan sensor proximity dan water flow sensor dengan input suara agar penyandang tunanetra sedikit banyak terbantu dalam melakukan kegiatan mengambil air minum secara aman dan mudah.

\section{METODE PENELITIAN}

\subsection{Diagram Alur Rangkaian}

Pada tahapan ini dirancang blok diagram sistem kerja smart dispenser. Alur sistem dapat dilihat pada gambar blok diagram 1. 


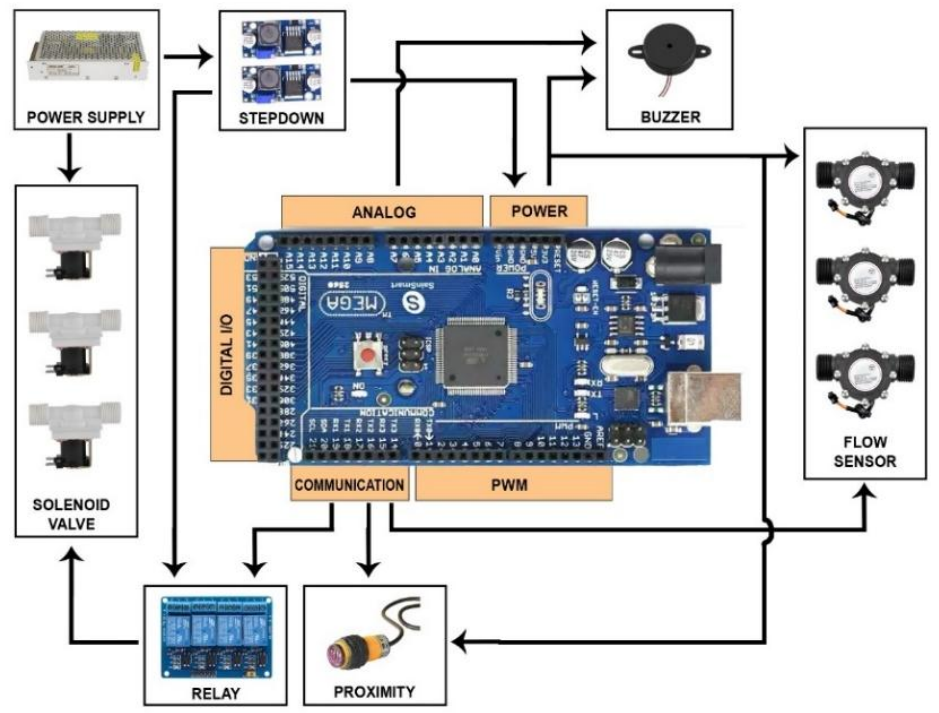

Gambar 1. Blok diagram sistem

Dari diagram blok pada Gambar 1 dapat diketahui komponen-komponen yang digunakan dalam proses penyelesaian alat smart dispenser. Berikut dengan alur kerja dari sistem tersebut. Dalam penelitian ini arduino mega2560 sebagai pengolah data, dan terdapat beberapa komponen penunjang dalam penyelesaian sistem tersebut, yakni:

1. Arduino mega 2560

2. Sensor infrared proximity

3. Selenoid valve

4. Water flow sensor

5. Modul relay

6. Rangkaian stepdown

7. Buzzer

Proses kerja sistem tersebut dimulai ketika sensor infrared proximity mendeteksi keberadaan gelas dimana alas penampang sudah didesain agar gelas mudah dalam peletakannya dan ujung selang dapat berada tepat diatas gelas yang telah diletakkan. Kemudian selenoid valve akan otomatis terbuka setelah mendapatkan input suara dari program delphi sebagai pengolah sinyal suara. Water flow sensor sendiri bertugas sebagai pengontrol volume air yang telah ditentukan. Apabila volume air sudah sesuai dengan perintah suara yang diimputkan, maka selenoid otomatis akan otomatis mati dan buzzer akan bekerja yang menandakan bahwa gelas sudah terisi air.

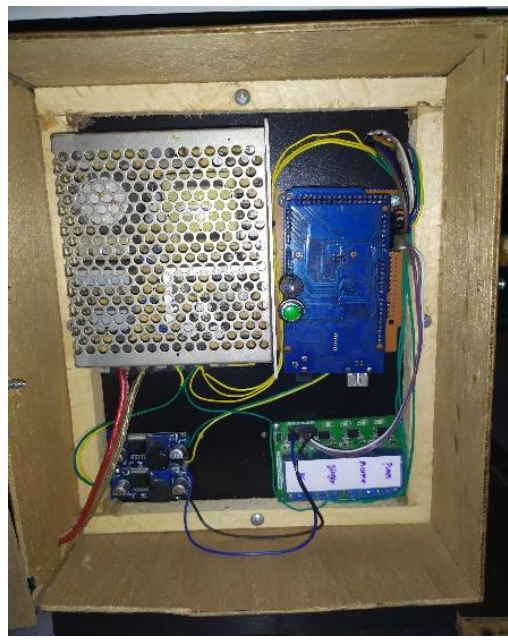

Gambar 2. Hasil perancangan 
Pada gambar 2. merukapan realisasi dari blok diagram pada gambar 1. Dihasilkan berupa beberapa komponen yang terintegrasi hingga membentuk sebuah sistem. Dan rangkaian tersebut ditempatkan pada control room system.

\subsection{Diagram alur sistem}

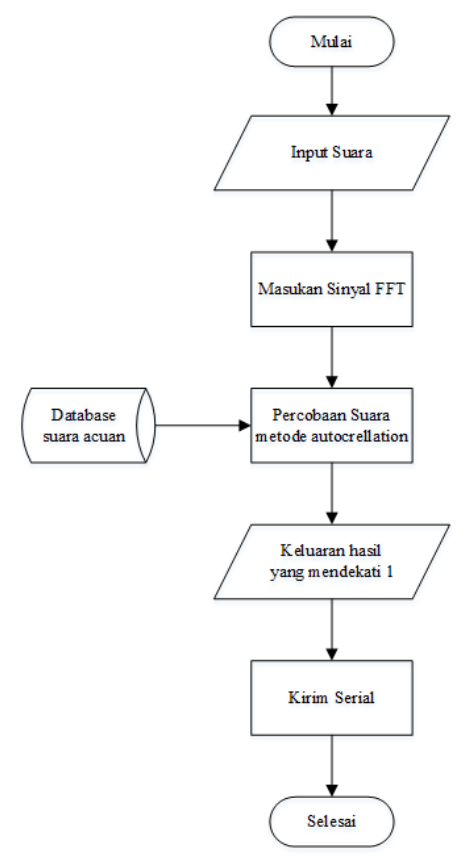

Gambar 3. flowchart pengolahan suara

Pada gambar 3 diatas merupakan flowchart proses pengolahan suara terdapat beberapa tahapan yaitu input suara, dimana kita memasukkan kata perintah untuk memilih jenis air minum yang diinginkan. Sistem bermula ketika input suara dengan menggunakan mikrofon dan didapatkan sinyal suaranya. Kemudian masuk pada proses memasukkan sinyal FFT (fast fourier transform) yaitu untuk mempresentasikan sinyal dalam domain waktu diskrit menjadi domain frekuensi, jadi hasil dari capture VAD akan menjadi inputan pada FFT yang akan menampilkan frekuensi dan amplitudo, sebelum itu sudah melalui proses VAD (Voice Activity Detection) yaitu sebagai proses pengidentifikasian keadaan voice atau silent dalam sebuah sinyal suara atau proses pemotongan suara yang tidak diperlukan. Hasil dari FFT tersebut akan dikorelasikan dengan database suara acuan dan akan diambil nilai yang sesuai atau nilai yang mendekati 1. Pencocokan suara tersebut menggunakan algoritma autocorrelation.,. Metode Autocorrelation merupakan cross-correlation dari suatu sinyal kepada sinyal itu sendiri. Pada pemrosesan sinyal cross-correlation merupakan metode pengukuran dari 2 gelombang sinyal sebagai fungsi jarak waktu antara 2 sinyal tersebut. proses tersebut akan membandingkan / mencocokkan data acuan dengan data input yang baru dengan menggunakan metode autocorrelation. Selanjutnya hasil dari autocorrelation akan dianalisa menggunakan logika keputusan untuk mendapatkan keputusan apakah suara acuan dan input suara tersebut sama. Setelah didapatkan hasil yang sama dengan data acuan. Maka hasil tersebut akan dikirim serial ke arduino mega 2560.

\section{HASIL DAN PEMBAHASAN}

Pada tahapan ini membahas tentang pengujian dan analisa terhadap hardware dan Sofware pada produk jadi smart dispenser.

\subsection{Pengujian hardware}

\subsubsection{Uji infrared proximity}

Tujuan pengujian dan analisis yang dilakukan pada sensor PIR adalah untuk mendapatkan parameter tentang jarak jangkauan sensor saat mendeteksi aktifitas manusia sehingga dapat disesuaikan dengan rancangan jarak jangkauan infrared proximity yaitu $3-80 \mathrm{~cm}$.

Tegangan input yang dibutuhkan sensor infrared proximity adalah $5 \mathrm{~V}$ DC. Pada pengujian sensor ini, dilakukan beberapa kali percobaan dengan jarak 3-7 cm menggunakan obyek gelas. Hal ini dilakukan untuk mendapatkan hasil yang maksimal terhadap respon sensor dengan obyek yang dideteksi. Pengujian dilakukan lima kali percobaan dan hasilnya diuraikan pada Tabel 1. 
Tabel 1. Perbandingan Pengujian Sensor Infrared proximity Terhadap Obyek

\begin{tabular}{lccccc}
\hline No & Jarak $(\mathbf{C M})$ & Obyek & $\begin{array}{c}\text { Jumlah } \\
\text { Percobaan }\end{array}$ & $\begin{array}{c}\text { Tingkat } \\
\text { Keberhasilan }\end{array}$ & $\begin{array}{c}\text { Keterangan } \\
\text { Obyek }\end{array}$ \\
\hline 1 & 3 & Gelas & 5 Kali & 5 Kali $(100 \%)$ & Mendeteksi \\
2 & 4 & Gelas & 5 Kali & 5 Kali $(100 \%)$ & Mendeteksi \\
3 & 5 & Gelas & 5 Kali & 5 Kali $(100 \%)$ & Mendeteksi \\
4 & 6 & Gelas & 5 Kali & 5 Kali $(100 \%)$ & Mendeteksi \\
5 & 7 & Gelas & 5 Kali & 5 Kali $(0 \%)$ & Tidak mendeteksi \\
6 & 8 & Gelas & 5 Kali & 5 Kali $(0 \%)$ & Tidak mendeteksi \\
7 & 9 & Gelas & 5 Kali & 5 Kali $(0 \%)$ & Tidak mendeteksi \\
8 & 10 & Gelas & 5 Kali & 5 Kali $(0 \%)$ & Tidak mendeteksi \\
9 & 11 & Gelas & 5 Kali & 5 Kali $(0 \%)$ & Tidak mendeteksi \\
10 & 12 & Gelas & 5 Kali & 5 Kali $(0 \%)$ & Tidak mendeteksi \\
\hline
\end{tabular}

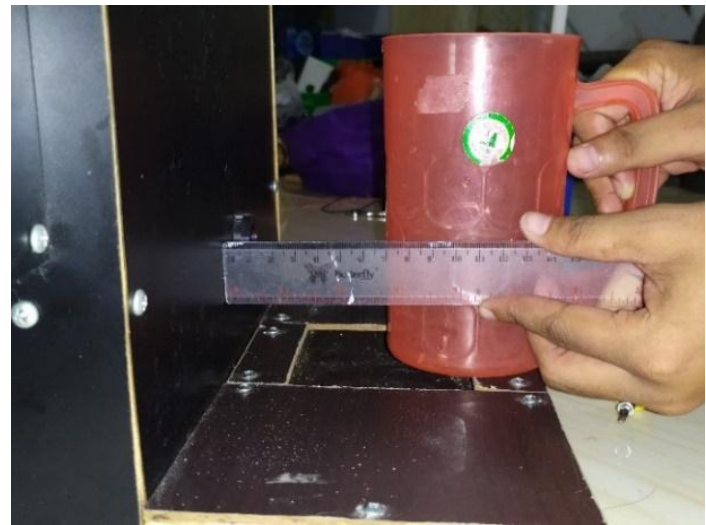

Gambar 4. Uji infrared proximity

Pada gambar 4 dilakukan percobaan dengan menggunakan gelas dengan jarak yang sudah ditentukan. Pada tabel 1. diatas dilakukan 10 kali percobaan pada masing-masing jarak, jarak yang akan di uji yaitu 3-12 cm. Infrared proximity memimiliki variable resistor didalam rangkaiannya, yang mana dapat dirubah jarak deteksi sesuai kebutuhan sistem. Dari ke 10 jarak tersebut hanya pada jarak $7 \mathrm{~cm}$ tidak dapat mendeteksi keberadaan gelas, dikarenakan variable resistor sudah di set sampai jarak deteksi maksimal pada $6 \mathrm{~cm}$. dan apabila gelas diletakkan lebih dari $7 \mathrm{~cm}$, proximity tidak akan mendeteksi gelas.

\subsubsection{Uji Water Flow Sensor}

Pengujian ini dilakukan pada waterflow sensor dengan hasil yang akan ditampilkan pada tabel 2. berdasarkan pengambilan data pada tabel tersebut dapat disimpulkan nilai error tertinggi $30 \%$ pada saat pengujian volume air $=250,550 \mathrm{ml}$, nilai error terendah $0 \%$ dan rata-rata error pembacaan waterflow sensor $11.11 \%$

Tabel 2. Uji Waterflow Sensor

\begin{tabular}{|c|c|c|c|c|c|}
\hline \multirow{2}{*}{ No } & \multirow{2}{*}{$\begin{array}{c}\text { Jumlah } \\
\text { percobaan }\end{array}$} & \multirow{2}{*}{ Jenis air } & \multicolumn{2}{|c|}{ Keterangan } & \multirow{2}{*}{ Presentase error } \\
\hline & & & Berhasil & Tidak & \\
\hline 1. & 10 & Panas kecil & 7 kali & 3 kali & $30 \%$ \\
\hline 2. & 10 & Normal kecil & 10 kali & - & $0 \%$ \\
\hline 3. & 10 & Dingin kecil & 8 kali & 2 kali & $20 \%$ \\
\hline 4. & 10 & Panas sedang & 9 kali & 1 kali & $10 \%$ \\
\hline 5. & 10 & Normal sedang & 9 kali & 1 kali & $10 \%$ \\
\hline 6. & 10 & Dingin sedang & 10 kali & - & $0 \%$ \\
\hline 7. & 10 & Panas besar & 10 kali & - & $0 \%$ \\
\hline 8. & 10 & Normal besar & 7 kali & 3 kali & $30 \%$ \\
\hline 9. & 10 & Dingin besar & 10 kali & - & $0 \%$ \\
\hline
\end{tabular}

Rata-rata error $=11.11 \%$ 


\subsection{Pengujian software}

Dalam tahapan software proses pengolahan suara terbagi menjadi beberapa bagian, yaitu proses simpan data acuan VAD, FFT dan proses pencocokan.

\subsubsection{Simpan data acuan VAD}

Pada proses simpan data acuan VAD dimaksud untuk mendapatkan sampel data suara yang sudah di potong atau digeser dimana sebelumnya data dalam pengambilan suara terdapat delay atau jeda. Sehingga sinyal suara berada pada posisi nol dan data suara dapan dengan mudah untuk dicocokkan. Jadi data hasil VAD di simpan dalam format (.txt).

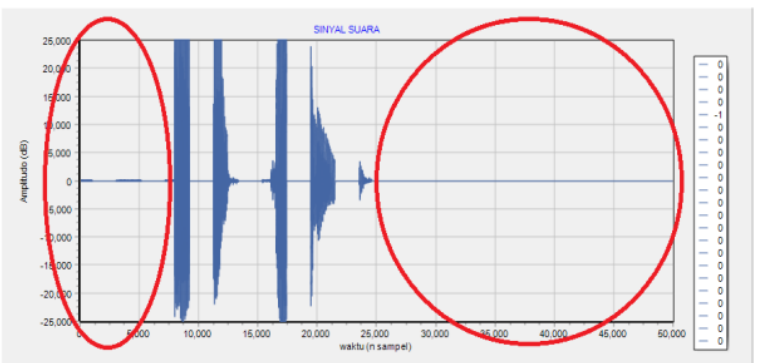

Gambar 5. Sinyal suara

Pada gambar 5. diatas, yang mewakili sinyal suara dari semua kata perintah dapat dilihat bahwa proses VAD merupakan proses pemotongan suara, yang akan dipotong dapat dilihat dari lingkaran merah. Dimaksudkan memotong suara pada kondisi silent atau memotong sinyal suara sehingga didapatkan sinyal suara seperti gambar 6. dibawah ini.

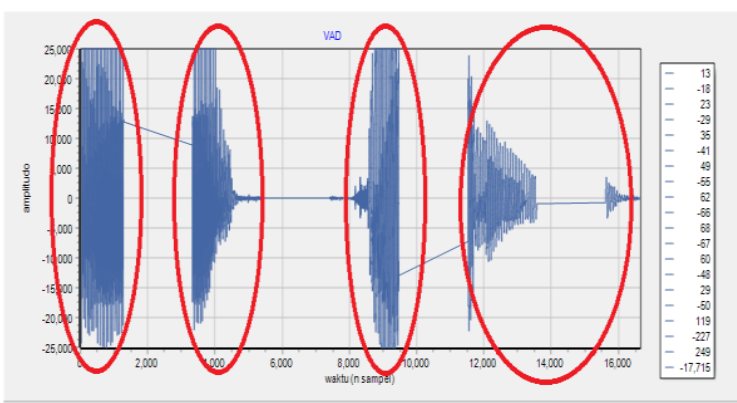

Gambar 6. Hasil VAD

Dari gambar diatas. Sinyal suara yang mengalami kenaikan amplitudo merupakan inputan suara perintah pa-cil atau panas kecil, sesuian lingkarang merah diatas.

\subsubsection{Simpan data acuan FFT}

Pada proses simpan data acuan FFT dimaksud untuk mendapat data sebelum dibandingkan, jadi data acuan tersebut perlu disimpan terlebih dahulu. Untuk proses penyimpanan data hasil dari VAD akan dipanggil dan diproses dengan metode FFT untuk mendapatkan hasil spektrum magnitude terhadap frekuensi dari suatu sinyal diskrit dan file FFT tersebut disimpan dalam format (.txt).

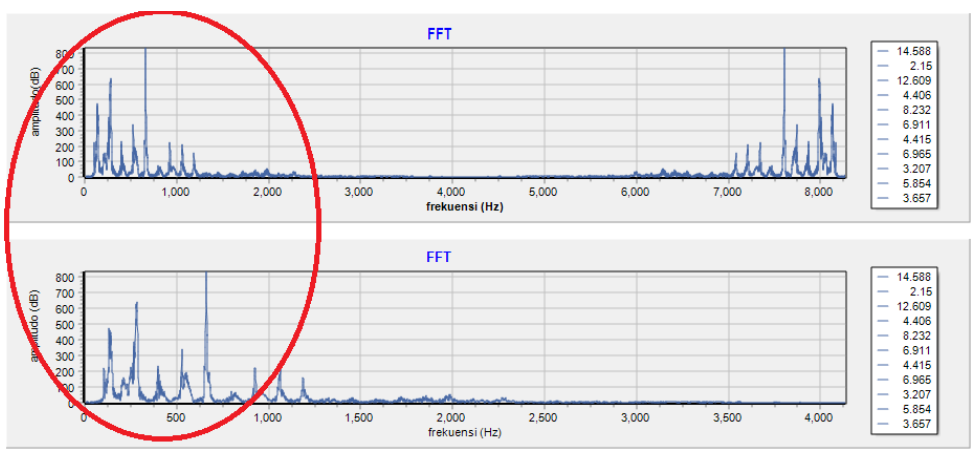

Gambar 7. Hasil FFT 
Dari gambar 7 didapatkan hasil fast fourier transfor. Dimana ketika gelombang sinyal memiliki nilai maka gelombang tersebut merupakan kondisi dimana perintah suara di inputkan. Gelombang suara tersebut menyentuh diatas amplitudo $800 \mathrm{~dB}$. Sedangkan frekuensi dari gelombang tersebut lebih dari $8.000 \mathrm{~Hz}$.

\subsubsection{Proses pencocokan suara}

Pengujian sampel uji menggunkan 10 input suara dengan orang yang berbeda, dimaksudkan untuk mengetahui keberhasilan dari suatu sistem aplikasi dalam proses pengolahan suara. Pengujian ini memiliki sembilan kata perintah yang masing-masing akan dilakukan oleh orang yang berbeda-beda. Tabel 3 dibawah ini adalah salah satu pengujian dengan menggunakan kata perintah pa-cil dengan maksud perintah panas kecil.

Tabel 3. uji suara pa-cil

\begin{tabular}{cccc}
\hline No & Sampel uji suara pa-cil (panas kecil) & Nilai korelasi & Keterangan \\
\hline 1 & & & Berhasil \\
2 & Fajar & 0,0697 & Berhasil \\
3 & Asrori & 0,1650 & Berhasil \\
4 & Roni & 0,3824 & Berhasil \\
5 & Dolet & 0,3647 & Tidak Berhasil \\
6 & Edi & 0,1955 & Tidak Berhasil \\
7 & Haris & 0,3747 & Berhasil \\
8 & Jawahir & 0,6792 & Berhasil \\
9 & Ifur & 0,5944 & Berhasil \\
10 & Ubed & 0,5181 & Berhasil \\
\hline
\end{tabular}

Dari pengujian sampel pemrosesan suara 'pa-cil' untuk kata apel aplikasi tingkat keberhasilan berdasarkan jarak mikropone saat bersuara dengan jarak kurang lebih $1 \mathrm{~cm}$. tingkat persentase error pada tiap parameter dapat dihitung dengan menggunakan rumus:

$$
\text { Presentase error }=\frac{\text { jumlah } \text { error }}{\text { jumlah } \text { data }} \times 100 \%
$$

Hasil dari pengujian sampel uji pemrosesan suara 'pa-cil' untuk kata panas kecil. Berdasarkan hasil uji suara microphone pada jarak kurang lebih $1 \mathrm{~cm}$ tingkat persentase error $20 \%$. Hasil persentase error 20 $\%$ disebabkan karena beberapa faktor yaitu gangguan atau noise kebisingan disekitar pada saat uji suara, dan bunyi suara tinggi rendahnya, serta perbedaan intonasi suara pada saat penyimpanan acuan suara dan pengujian suara. Sehingga menyebabkan ketidak sesuai saat pencocokan.

\subsection{Analisa}

Berdasarkan hasil pengujian seluruh sistem dapat dianalisa bahwa rancang bangun smart dispenser dengan voice recognition dapat bekerja dengan baik. Hal tersebut dapat dibuktikan dengan hasil pengujian alat perangkat keras (hardware) yang sesuai dengan inputan yang disampaikan atau dikirim berupa serial. Hasil pengujian sampel uji suara menggunakan microphone dengan jarak kurang lebih $1 \mathrm{~cm}$. Hasil pengujian pada waktu perekaman ada beberapa kondisi yang perlu diperhatikan yakni dalam kondisi terlalu ramai dan perbedaan menginputkan suara ketika m][enyimpan dan pengujian akan mempengaruhi presentase kecocokan yang mengakibatkan ketidak sesuaian keluaran yang disampaikan.

Dari semua data error dapat diambil rata-rata error sistem tersebut yaitu:

Tabel 4. Hasil sistem

\begin{tabular}{ccc}
\hline No & Sampel kata & Presentase error \\
\hline 1 & Panas kecil & $20 \%$ \\
2 & Panas sedang & $30 \%$ \\
3 & Panas besar & $0 \%$ \\
4 & Normal kecil & $20 \%$ \\
5 & Normal sedang & $50 \%$ \\
6 & Normal besar & $30 \%$ \\
7 & Dingin kecil & $40 \%$ \\
8 & Dingin sedang & $50 \%$ \\
9 & Dingin besar & $40 \%$ \\
\hline \multicolumn{3}{c}{ Rata-rata error $=31,11 \%$} \\
\hline
\end{tabular}


Dari tabel diatas. Dapat disimpulkan bahwa tingkat keberhasilan dari sistem ini yaitu $100-31,11=$ $68,89 \%$. hal-hal yang mempengaruhi keakuratan sistem tersebut dikarenakan kondisi backround dalam pengambilan sampel dan uji suara terlalu ramai atau noise.

\section{KESIMPULAN}

Berdasarkan hasil perancangan, implementasi, dan pengujian hasil dari sistem yang telah dibuat dapat diambil kesimpulan sebagai berikut:

1. Dari hasil penelitian ini dapat menciptakan produk smart dispenser menggunakan voice recognition secara realtime dengan pengolahan suara dilakukan pada laptop.

2. Pengujian alat dapat bekerja secara baik.

3. Pada saat perekaman perbedaan intonasi suara pada saat penyimpanan acuan suara dan uji suara akan sangat berpengaruh terhadap output yang dihasilkan .

4. Faktor-faktor yang dapat mempengaruhi ketidak efektifan hasil suara dapat berupa adanya noise yang terlalu besar, sehingga pada saat pengambilan suara dibutuhkan tempat yang kedap suara.

Hal yang mengenai keakurasian aplikasi voice recognition. Dapat disimpulkan bahwa tingkat keberhasilan dari sistem ini yaitu $68,89 \%$. Keakuratan sistem tersebut dikarenakan kondisi backround dalam pengambilan sampel dan uji suara terlalu ramai atau noise, dapat pula berupa perbedaan intonasi atau panjang pendeknya pengucapan pada saat penyimpanan dan uji hasil suara.

\section{DAFTAR PUSTAKA}

[1] Asep Kurniawan, "Alat Bantu Jalan Sensorik Bagi Tunanetra," Journal of Disability Studies, Vol. 6, No. 2, pp. 285-312, 2019.

[2] G. pindhika, Wisnu Wendanto, "Rancang Bangun Dispenser Otomatis Berbasis Mikrokontroler Atmega 16," JURNAL ILMIAH GO INFOTECH, Vol. 21, No.1, pp. 1-6, 2015.

[3] B. Catabang and Rionel B. Carlo, "implementation of Speech Recognition using MFCC for Plant Watering and Lighting System," LPU-Laguna Journal of Engineering and Computer Studies, Vol. 3, No.3, pp. 55-63, Oct 2016.

[4] Mahalakshmi P., et al., "Voice Recognition Security System Using Mel-Frequency cepstrum Coefficients," ASIAN JOURNAL OF PHARMACEUTICAL AND CLINICAL RESEARCH, vol. 9,suppl.3, pp. 131-138, 2016.

[5] Khin Nyein Win, et al., "Automatic Water Storage and Distribution System using Reliance SCADA," International Journal of Trend in Scientific Research and Development (IJTSRD), vol. 3, pp. 698-702, Aug 2019.

[6] Fitri Haryono, Paryanta, "Rancang bangun alat memilih minuman dengan peritah suara berbasis arduino". Surakarta, Teknik komputer, STMIK AUB Surakarta. 2017.

[7] Mulyani, Rini, "Pemetaan dan analisis tipe suara manusia menggunakan Fast Fourier Transform (FFT)". skripsi . Lampung. Fakultas Matematika Dan Ilmu Pengetahuan Alam. Universitas Lampung. 2017.

[8] Wahyu Dani akhmad, dkk, "perancangan aplikasi voice command recognition berbasis android dan arduino uno", Jakarta, Program studi Teknik Elektro, Universitas Mercu Buana, 2016.

[9] Desi Triyanawati, Riza Alfita, dan Kunto Aji Wibisono, "Rancang bangun voice recognition sebagai controller penggunaan perangkat elektronik pada pasien difabel", Bangkalan, Jurusan Teknik Elektro, Universitas Trunojoyo Madura, 2018.

[10] Rian L.singgeta, dkk, "rancang bangun dispenser air bersih otomatis berbasis web menggunakan teknologi RFID", Manado, Program studi teknik elektro, Universitas Sam Ratulangi Manado, 2019. 